\title{
Should One Sell Domestic Firms to Foreign Ones? A Tale of Delegation, Acquisition and Collusion.
}

\author{
Davide Dragone \\ Department of Economics, University of Bologna \\ Strada Maggiore 45, 40125 Bologna, Italy \\ davide.dragone@unibo.it
}

January 18, 2008 


\begin{abstract}
In a model of repeated Cournot competition under complete information, I show how the existence of a fringe of managerial firms affects the stability of a cartel of strict profit-maximizing firms. There always exists a critical dimension of the fringe that makes the cartel unstable, and this dimension is non-monotone in the total number of firms. By appropriately selecting the dimension of the fringe, a policy maker can affect the equilibrium outcome. As an example, I consider the case of a domestic authority that is contemplating whether to allow entry of a fringe of managerial foreign firms in the domestic market to increase the competitive pressure, thereby enhancing domestic welfare.
\end{abstract}

JEL Classification: D43; L13; L21.

Keywords: Delegation, Cournot oligopoly, Cartel stability, Fringe. 


\section{Introduction}

The issue of cartel stability has a long tradition. Several contributions have studied the factors and conditions affecting firms' ability to implement collusive practices over time, investigating, for example, the consequences of heterogeneity among agents (see, inter alia, d'Aspremont et al. (1983), Donsimoni (1985), Donsimoni et al. (1986)), the role of imperfect information (Green and Porter (1984), Rothschild (1999)) and of product differentiation (Ross (1992), Deneckere (1983)), the effect of the imposition of import quotas (Rotemberg and Saloner, (1986)) or the consequences that fringes of non-colluding firms have on cartel stability (Shaffer (1995)).

The standard theoretical framework assumes profit-maximizing firms whose strategic variables are quantities and prices. Lambertini and Trombetta (2002) show that the stability of a cartel is also affected by strategic delegation. In a Cournot oligopoly, strategic delegation implies that owners delegate output decisions to managers whose objective functions differ from the owners'. When managerial incentives are a mix of profits and sales, managers behave aggressively and expand their output beyond the familiar Cournot Nash equilibrium. In the one-shot non-cooperative game, hiring managers is a dominant strategy in that delegation makes the firm more aggressive under Cournot competition and creates a credible commitment towards output expansion. In equilibrium output is larger and prices are lower as compared to the Cournot Nash equilibrium, thereby reducing profits and increasing consumer surplus (Fershtman, 1985, Vickers, 1985). Considering a repeated Cournot oligopoly between two firms, Lambertini and Trombetta (2002) show that delegation can make the cartel more unstable when owners collude in setting the incentives schemes, because it makes deviation from the cartel more appealing compared to a situation where firms are strict profit-seeking agents.

In the literature on cartel stability, much attention has been devoted to the stability of cartels of firms when there exists a competitive fringe (inter alia, d'Aspremont et al. (1983), Donsimoni et al. (1985), Donsimoni et al. (1986), Thoron (1998)). Yet, if the number of firms in the industry is relatively small, the fringe firms do not necessarily behave as price-takers. Konishi and Lin (1999) and Shaffer (1995) consider an oligopoly where fringe firms make output decisions after the cartel has chosen its output level. In 
this paper, I adopt the same model as Vickers (1985) and Lambertini and Trombetta (2002), in which all output choices are taken simultaneously, and I extend the idea that delegation is a relevant strategic variable for cartel stability by considering how a cartel between owners of pure profitseeking firms that maximize joint profits is affected by a fringe of managerial firms. I show that it is always possible to make the cartel between owners unstable by appropriately selecting the dimension of the fringe, and that such a dimension is non-monotone in the total number of firms operating in the market.

I apply this set up to a situation where a domestic planner cares about consumer surplus and the profits of the domestic firms operating in the market. The planner must choose how many foreign managerial firms (which will constitute the fringe) she should allow to enter the domestic market through the acquisition of domestic firms. From the perspective of the domestic planner, I show that it is never optimal to allow the entry of foreign managerial firms when the market is very concentrated because the increase in output brought about by entry is not sufficiently counterbalanced by the reduction in profits accruing to the domestic firms. When the market is more fragmented and the incumbents are patient enough, it may be optimal to allow managerial firms to get in, as the competitive pressure exerted by entrants makes the cartel between domestic owners unstable, with the result that, after entry, all firms delegate and domestic welfare increases.

The remainder of the paper is organized as follows. Section 2 introduces the model. In Section 3, I study the optimal output choices made by managers once the incentive schemes are chosen by the owners of the firms. Depending on whether the domestic planner has allowed any entry and depending on the type of equilibrium outcome, four different cases can be distinguished. In Section 4, I separately study the four outcomes and determine the incentive schemes, the optimal output levels and the profits accruing to the domestic and foreign firms. In Section 5, I determine the optimal number of managerial firms that should be allowed in the market in case of entry. In Section 6, I compare the levels of domestic welfare associated to the four equilibria, and I determine the conditions that bring a domestic planner to choose whether and how many foreign firms should be let in the domestic market. Section 7 concludes. 


\section{The Set up}

In an oligopolistic market, $n$ firms compete in quantities for a homogeneous good whose inverse demand function is

$$
p=a-Q
$$

where $Q$ is total output and $a$ is the reservation price. Under the assumption that production takes place at constant returns to scale, the profit function of each firm is the following:

$$
\pi=(p-c) q
$$

where $q$ is the output produced by the firm and $c$ is the unit production cost, with $a>c \geq 0$.

The delegation game proposed by Vickers (1985) introduces for a firm's owner the option to delegate control of output decisions to a manager whose objective is

$$
\max _{q} M=\pi+\theta q,
$$

where parameter $\theta$ is a measure of the relevance of sales and is chosen by the owner of the firm to maximize profits. The incentive function in (3) is equivalent to assume that managers maximize a linear combination of profits and revenues, profits and costs, or sales and costs (d'Aspremont and Gerard-Varet (1980), Fershtman (1985), Fershtman and Judd (1987), Katz (1986), Sklivas (1987)). The special case $\theta=0$ implies that the manager maximizes the same objective function as the owner would, and that there is no difference in the output levels produced by an entrepreneurial firm and a managerial one. In other words, $\theta=0$ is equivalent to say that the owner hires no manager. In the remainder, I adopt the following:

Assumption 1. $\theta$ is non-negative.

In the non-cooperative subgame perfect equilibrium of the delegation game the non-negativity assumption on $\theta$ turns out to be non-binding (Vickers, 1985). Yet, when owners collude between them to maximize joint profits, the optimal amount of delegation is negative (Lambertini and Trombetta, 2002). Clearly, this is a conceivable outcome, but the empirical evidence 
points in the opposite direction, suggesting that managers do not place a negative weight on sales (Murphy, 1995, Baker et al., 1988).

Consider now the case in which $m$ firms, which constitute the fringe of managerial firms, are allowed to enter the oligopolistic market according to the following:

Assumption 2. The number of firms in the market is constant over time.

This amounts to assume that no mergers are allowed for and that fringe firms can enter the market only through acquisition of $m \in[0, n]$ entrepreneurial incumbents. In the remainder of the paper, I will refer to the entrants as the 'foreign firms' and to the incumbents as the 'domestic firms'. When $m=0$, no foreign firm enters the market. Fringe firms are identical to the incumbents: owners are profit-maximizers and managers maximize a mix of profits and sales. The only difference is in the set of delegation options, as foreign firms are always managerial, while the incumbents have the option to be either managerial or strict profit-seekers.

The number of foreign entrants is regulated by a domestic social planner whose domestic social welfare function is given by the sum of the profits accruing to the domestic firms and consumer surplus:

$$
N S W(m)=(n-m) \pi_{i}+C S,
$$

where $\pi_{i}$ is the individual profit of a domestic firm ( $i$ stands for incumbent) and $C S$ is consumer surplus. The domestic planner chooses the dimension $m$ of the fringe, taking into account the following game with complete and symmetric information:

Stage 1: The domestic planner allows $m$ foreign managerial firms to buy $m$ domestic firms.

Stage 2: Firms'owners simultaneously choose the incentive scheme of their manager.

Stage 3: Firm's managers simultaneously choose the output level.

When owners are simultaneously choosing whether to delegate or not, delegation is the dominant strategy of the one-shot noncooperative game 
(see, inter alia, Vickers (1985), Basu (1987), Fershtman and Judd (1987), Sklivas (1987), Fershtman (1985), Katz (1986)). As this game is repeated infinitely many times, there is scope for stable forms of collusion. In this paper I focus on collusion occurring at stage 2, where the owners of the firms choose their organizational structure and determine the incentive scheme of their managers. To study the stability of these collusive agreements in front of a fringe of non-colluding firms (the 'foreigners'), I assume the following:

Assumption 3: Foreign owners always delegate to managers.

The assumption above implies that only domestic owners have the option to collude by not delegating output choices to managers. The stability of the collusive agreement is assessed considering Friedman's grim trigger strategy (Friedman, 1971) in which players collude as long as all the others do so. After detecting a deviation by any of the participants to the cartel, all the cartel members revert to the non-cooperative equilibrium strategy (i.e. they set a positive $\theta$ ) forever. Let $\delta \in[0,1]$ be the intertemporal discount factor of the owner of a firm and adopt the following assumption:

Assumption 4. $\delta_{i}=\delta$ for all owners of domestic firms.

As the attention is focused only on the stability of the cartel between domestic owners, no specific assumption on the intertemporal discount factor of foreign owners and of domestic/foreign managers is needed ${ }^{1}$.

\section{Output choices}

To solve the model, I proceed by backward induction considering the output choices that managers face at stage three, once the owners of the firms have chosen the amount of delegation $\theta \geq 0$ (where $\theta=0$ is the limit case in which the manager is a pure profit-seeker or, equivalently, the owner hires no manager). Rewrite the objective function (3) of a manager with delegation $\theta_{k}$, for all $k, j \in\{1, \ldots, n\}$, as follows:

$$
M_{k}=\left(a-c-\theta_{k}-\Sigma_{j \neq k} q_{j}-q_{k}\right) q_{k} .
$$

\footnotetext{
${ }^{1}$ Equivalently, we could assume that their discount factors are high enough to ensure that collusion is unstable; see Lambertini and Trombetta (2002) for a complete analysis of cartel stability where both owners and managers collude.
} 
The first-order condition that firm $k$ 's manager considers in the market subgame is

$$
\frac{\partial M_{k}}{\partial q_{k}}=a-c-\theta_{k}-\Sigma_{j \neq k} q_{j}-2 q_{k}=0
$$

Solving for all managers yields the optimal quantity produced by each firm as a function of the delegation parameters chosen by the owners, the market structure and the production costs (Sklivas $(1987))^{2}$ :

$$
q_{k}=\frac{a-c+n \theta_{k}-\Sigma_{j \neq k} \theta_{j}}{n+1} .
$$

The optimal output level of firm $k$ is increasing in the amount of delegation chosen by its owner and decreasing in the delegation choices of the other firms. This implies the familiar result that, everything else equal, a managerial firm expands her output more than a profit-seeking firm (Vickers, 1985). Substituting and rearranging, total output and the profit accruing to each firm $k$ can be written as follows, respectively:

$$
\begin{aligned}
Q & =\frac{n(a-c)+\Sigma_{k=1}^{n} \theta_{k}}{1+n} \\
\pi_{k} & =\frac{\left(a-c-\theta_{k}-\Sigma_{j \neq k} \theta_{j}\right)\left(a-c+n \theta_{k}-\Sigma_{j \neq k} \theta_{j}\right)}{(n+1)^{2}} .
\end{aligned}
$$

The optimal amount of delegation of each manager $k$ depends on the delegation choices of the owners of the remaining firms. As the delegation choices depend on whether the domestic social planner has allowed any domestic firm to enter the market (stage 1) and on the stability of the cartel between the domestic owners (at stage 2), four different outcomes can occur:

(i) no foreign firm is allowed to enter the market $(m=0)$ and the domestic owners set the incentive schemes non-cooperatively,

(ii) no foreign firm is allowed to enter the market $(m=0)$ and domestic's owners collude,

(iii) $m \geq 1$ foreign firms enter the market and the domestic's owners play non-cooperatively,

(iv) $m \geq 1$ foreign firms enter the market and the domestic's owners collude.

\footnotetext{
${ }^{2}$ At this stage we do not need to specify whether the firm is managerial or profitseeking, and the reaction functions of firm $k$ 's manager can be obtained without requiring symmetry.
} 
For further reference, I will refer to the first outcome as the (D) equilibrium with no entry (where $\mathrm{D}$ stands for delegation), which corresponds to the solution of the delegation game by Vickers (1985) where all firms adopt symmetric managerial incentives and behave aggressively by expanding their output beyond the Cournot Nash quantities. In case (ii), the owners optimally collude by not hiring managers, which implies that the delegation game reduces to a standard Cournot oligopoly with $n$ identical firms. I will refer to the associated equilibrium as to the (C) outcome. In cases (iii) and (iv), the domestic planner has allowed a fringe of managerial firms to enter the market. In case (iii) all domestic and foreign owners delegate; I will refer to it as the (D) outcome with entry. It is worth stressing that, given the symmetry between incumbents and entrants, the optimal amount of delegation, the individual production levels and profits are the same as those of case (i). The only differences between case (i) and case (iii) concerns the level of domestic social welfare, that in case (iii) is clearly reduced by the profits accruing to the non-domestic firms. In case (iv) the domestic owners collude (by not hiring managers) and the foreigners constitute a fringe of managerial firms. As this case corresponds to a Stackelberg outcome, I will refer to it as the $(\mathrm{S})$ outcome.

\section{Delegation choices}

In this Section, I consider the second stage of the game. I separately consider the four possible outcomes that can occur and determine the optimal incentive schemes, the corresponding output levels and individual profits. When collusion is profitable, I compute the critical value of the discount factor (which, in case of entry, also depends on the number of entrants) above which collusion is a stable outcome.

First, consider the cases where only domestic incumbents operate in the market. When $m=0$, two possible equilibria can occur, depending on the intertemporal discount factor of the domestic owners, where either all of them delegate to managers or collude by not delegating. 


\section{1 (D) outcome, $m=0$.}

When all domestic owners $i, j \in\{1, \ldots, n\}$ delegate to managers, the optimal amount of delegation is found solving the first-order condition $\partial \pi_{i} / \partial \theta_{i}=0$, which yields (Vickers, 1985):

$$
\theta_{i}=\frac{(n-1)\left(a-c-\Sigma_{j \neq i} \theta_{j}\right)}{2 n}
$$

By imposing symmetry, the following optimal amount of delegation :

$$
\theta_{i}^{D}=(a-c) \frac{(n-1)}{n^{2}+1}>0 .
$$

Substituting $\theta_{i}^{D}$ in the expressions (7)-(9), I get the following output levels and individual profits:

$$
\begin{aligned}
q_{i}^{D} & =(a-c) \frac{n}{n^{2}+1} \\
Q^{D} & =(a-c) \frac{n^{2}}{n^{2}+1} \\
\pi_{i}^{D} & =(a-c)^{2} \frac{n}{\left(1+n^{2}\right)^{2}}
\end{aligned}
$$

\section{2 (C) outcome, $m=0$.}

In case all domestic owners collude, they choose the delegation profile $\left\{\theta_{1}, \ldots, \theta_{n}\right\}$ that maximizes the following joint profit function:

$$
\begin{aligned}
\Pi & =\sum_{i=1}^{n} \pi_{i} \\
& =\frac{1}{(n+1)^{2}}\left(a-c-\sum_{i=1}^{n} \theta_{i}\right)\left[n(a-c)+\sum_{i=1}^{n} \theta_{i}\right]
\end{aligned}
$$

subject to the non-negativity condition on $\theta_{i}$. Taking the derivative with respect to each $\theta_{i}$ yields:

$$
\frac{\partial \Pi}{\partial \theta_{i}}=-\frac{1}{(n+1)^{2}}\left[(n-1)(a-c)+2 \theta_{i}+2 \Sigma_{i \neq j} \theta_{i}\right]
$$

As $\theta \geq 0$, the partial derivative computed above is strictly negative, which implies that the optimal (corner) solution is $\theta_{i}=0$ for all domestic own$\mathrm{ers}^{3}$. In other words, when the domestic owners collude to maximize joint

\footnotetext{
${ }^{3}$ If $\theta$ were unrestricted, the joint profit function (that is strictly concave because it is the sum of strictly concave functions) would be maximized when the following condition
} 
profits, the optimal choice is to hire no manager and behave as pure profitmaximizers. When this is the case, the following output levels and individual profits result:

$$
\begin{aligned}
q_{i}^{C} & =(a-c) \frac{1}{n+1} \\
Q^{C} & =(a-c) \frac{n}{n+1} \\
\pi_{i}^{C} & =(a-c)^{2} \frac{1}{(1+n)^{2}} .
\end{aligned}
$$

Note that, compared with the (D) outcome, the Cournot Nash outcome is associated to a lower output. This implies higher individual profits but a lower level of consumer surplus, with the consequence that the level of social welfare associated to the (C) outcome is lower than the one associated with the (D) outcome with no entry.

To assess the conditions that make case $(\mathrm{C})$ stable, I need to determine the deviation profits accruing to a domestic owner that does not set $\theta=0$, while all the others do. Maximizing the profit function (9) with respect to $\theta_{k}$ the following reaction function obtains (Vickers, 1985):

$$
\theta_{k}=\frac{(n-1)\left(a-c-\Sigma_{j \neq k} \theta_{j}\right)}{2 n} \text { for } k, j \in\{1, \ldots, n\}
$$

If $\theta_{j}=0$ for all $j \neq k$, the optimal deviation requires (Vickers, 1985):

$$
\theta_{d}(0)=\frac{(a-c)(n-1)}{2 n}
$$

where the zero in brackets signals this is the case of no entry and the pedix 'd' stands for defection. The corresponding deviation profit is

$$
\pi_{d}(0)=\frac{(a-c)^{2}}{4 n}>\pi^{C} .
$$

By considering trigger strategies, collusion between domestic owners is stable if

$$
\delta>\delta^{*}(n, 0)=\frac{\pi_{d}(0)-\pi^{C}}{\pi_{d}(0)-\pi^{D}}=\frac{\left(1+n^{2}\right)^{2}}{(1+n)^{4}}
$$

holds: $\sum_{i=1}^{n} \theta_{i}=-\frac{(n-1)(a-c)}{2}<0$. If the owners adopt symmetric incentive schemes, the optimal solution is $\theta_{i}=-\frac{(n-1)(a-c)}{2 n}$ that, for the case $n=2$ simplifies to $\theta_{i}=-\frac{(a-c)}{4}$ (see Lambertini and Trombetta, 2002). 
(see Lambertini and Trombetta, 2002), where $\pi^{C}$ and $\pi^{D}$ are, respectively, the profits accruing to the owner of the domestic firm in the collusive and in the delegating equilibrium with no entry. The zero appearing in brackets signals this is the case where $m=0$.

\section{3 (D) outcome, $m \geq 1$}

Now consider the case where $m \in\{1, \ldots, n\}$ managerial foreign firms have entered the market. As entrants and incumbents face the same technology and the good is homogeneous, the only difference between them is that the incumbents have the option to collude. Clearly, when they all delegate this difference is lost and the same $\theta$ 's, output levels, individual profits and consumer surplus as in the (D) case with no entry . All equilibrium outcomes only depend on fixed parameters such as the reservation price, the unit cost of production and the total number of firms in the market. Hence, the number of entrants $m$ is relevant only to compute the level of domestic social welfare.

\section{4 (S) outcome, $m \geq 1$}

Consider now the case in which the domestic planner has allowed $m \in$ $\{1, \ldots, n\}$ managerial firms to buy $m$ incumbents and the remaining $n-m$ incumbents collude by choosing the profile of delegation that maximizes joint profits. Before proceeding note that the $(\mathrm{S})$ outcome requires $m$ to lie in the interval $[1, n-2]$, with $n \geq 3$. The lower bound is necessary because we are in the case in which entry occurs, the upper bound because the domestic firms must be at least two to collude.

I proceed by first assessing the maximum number of entrants that makes collusion between domestic owners profitable; then I determine the conditions for cartel stability. With reference to trigger strategies, stability can be assessed in terms of the critical value of the intertemporal discount factor that makes collusion stable. Equivalently, the same condition can be expressed as a function of the dimension of the fringe. The advantage of the latter condition is that, given $n$ and $\delta$, it informs about the critical dimension of the fringe that makes the cartel between domestic incumbents unstable. This implies that the domestic social planner can influence the equilibrium outcome by appropriately choosing the dimension of the fringe. 
For expositional convenience, let the entrants be indicated by $e, f \in$ $\{1, \ldots, m\}$ and the incumbents by $i \in\{m+1, \ldots, n\}$. Consider first the delegation choices made by the foreign owners. They choose non-cooperatively the optimal amount of delegation that maximizes the objective function in (9), that can be written as follows:

$$
\pi_{e}=\frac{\left(a-c-\theta_{e}-\Sigma_{f \neq e} \theta_{f}-\Sigma_{i=m+1}^{n} \theta_{i}\right)\left(a-c+n \theta_{e}-\Sigma_{f \neq e} \theta_{f}-\Sigma_{i=m+1}^{n} \theta_{i}\right)}{(n+1)^{2}} .
$$

The associated first-order condition is:

$$
\frac{\partial \pi_{e}}{\partial \theta_{e}}=\frac{1}{(n+1)^{2}}\left[(n-1)(a-c)-2 n \theta_{e}+(n-1) \Sigma_{f \neq e} \theta_{f}+(n-1) \Sigma_{i=m+1}^{n} \theta_{i}\right] .
$$

Now consider the domestic owners. They choose the profile $\left\{\theta_{m+1}, \ldots, \theta_{n}\right\}$ that maximizes the following joint profit function:

$$
\begin{aligned}
\Pi= & \sum_{i=1}^{n-m} \pi_{i} \\
= & \frac{1}{(n+1)^{2}}\left(a-c-\sum_{i=m+1}^{n} \theta_{i}-\Sigma_{e=1}^{m} \theta_{e}\right) \cdot \\
& {\left[(n-m)(a-c)+(m+1) \Sigma_{i=m+1}^{n} \theta_{i}-(n-m) \Sigma_{e=1}^{m} \theta_{e}\right] }
\end{aligned}
$$

To find the optimal solution, rewrite equation (26) as

$$
\begin{aligned}
\Pi= & \frac{1}{(n+1)^{2}}\left(a-c-\theta_{m+1}-\Sigma_{i=m+2}^{n} \theta_{i}-\Sigma_{e=1}^{m} \theta_{e}\right) \cdot \\
& {\left[(n-m)(a-c)+(m+1) \theta_{m+1}+(m+1) \Sigma_{i=m+2}^{n} \theta_{i}-(n-m) \Sigma_{e=1}^{m} \theta_{e}\right] }
\end{aligned}
$$

where $\theta_{m+1}$ is the amount of delegation chosen by one of the domestic owners. The partial derivative of the joint profit function with respect to $\theta_{m+1}$ yields:

$$
\begin{aligned}
\frac{\partial \Pi}{\partial \theta_{m+1}}= & \frac{1}{(n+1)^{2}}\left[(1+2 m-n)(a-c)-2(1+m)\left(\theta_{m+1}+\sum_{i=m+2}^{n} \theta_{i}\right)+\right. \\
& \left.-(1+2 m-n) \sum_{e=1}^{m} \theta_{e}\right]
\end{aligned}
$$

I now assume that the domestic owners adopt a symmetric solution, so that $\theta_{m+1}=\ldots=\theta_{n}=\theta_{i}^{S}$, where apex $S$ stands for Stackelberg outcome. Note also that, as all foreign owners are identical, in equilibrium they adopt a 
symmetric solution $\theta_{e}=\theta_{f}=\theta_{e}^{S}$ for all $e, f \in\{1, \ldots, m\}$. This allows to simplify the first-order conditions (25) and (28) as follows

$$
\begin{aligned}
\frac{\partial \pi_{e}}{\partial \theta_{e}}= & \frac{1}{(n+1)^{2}}[(n-1)(a-c)+ \\
& \left.-(n m+n-m+1) \theta_{e}^{S}-\left(n^{2}-n m-n+m\right) \theta_{i}^{S}\right] \\
\frac{\partial \Pi}{\partial \theta_{i}}= & \frac{1}{(n+1)^{2}}[(a-c)(1+2 m-n)+ \\
& \left.-2(n-m)(1+m) \theta_{i}^{S}-m(1+2 m-n) \theta_{e}^{S}\right] .
\end{aligned}
$$

When $m<\frac{n-1}{2}$, the partial derivative of the joint profit function (30) is negative and, as in the case of collusion with no entry considered in the previous section, the non-negativity restriction implies that the optimal choice of the $n-m$ domestic owners is to set $\theta_{i}^{S}=0$ for all $i \in\{1, \ldots, n-m\}^{4}$. Accordingly, the $m$ foreign owners choose the optimal amount of delegation that solves the following condition

$$
\frac{\partial \pi_{e}}{\partial \theta_{e}}=\frac{1}{(n+1)^{2}}\left[(n-1)(a-c)-2 n \theta_{e}^{S}+(n-1) \Sigma_{e \neq f} \theta_{f}^{S}\right]=0
$$

where $e, f \in\{1, \ldots, m\}$. Exploiting symmetry, the optimal amount of delegation for the foreign entrants is:

$$
\theta_{e}^{S}=(a-c) \frac{n-1}{n-m+n m+1}
$$

Substituting $\theta_{e}^{S}$ in the reaction function of the managers (7) and rearranging I obtain the output levels of the domestic entrants and the foreign incumbents, respectively:

$$
\begin{aligned}
q_{e}^{S}(m) & =(a-c) \frac{n}{n-m+n m+1} \\
q_{i}^{S}(m) & =(a-c) \frac{1}{n-m+n m+1}
\end{aligned}
$$

where $m$ signals that these outcomes depend on the number of entrants.

\footnotetext{
${ }^{4}$ The Appendix contains the computations showing that, with $m \geq(n-1) / 2$, collusion between incumbents is never profitable.
} 
The associated total output levels and individual profits are, respectively,

$$
\begin{aligned}
Q^{S}(m) & =(a-c) \frac{n m+n-m}{n+n m-m+1} \\
\pi_{e}^{S}(m) & =(a-c)^{2} \frac{n}{(n-m+n m+1)^{2}} \\
\pi_{i}^{S}(m) & =(a-c)^{2} \frac{1}{(n-m+n m+1)^{2}}
\end{aligned}
$$

Comparing $\pi_{i}^{S}(m)$ with $\pi_{i}^{D}$ to check when collusion between incumbents is profitable yields:

$$
\pi_{i}^{S}(m)-\pi_{i}^{D}=(a-c)^{2} \frac{(n-1)\left(n^{3}-n^{2} m^{2}-2 n^{2} m+m^{2} n-2 m n-1\right)}{\left(1+n^{2}\right)^{2}(n-m+n m+1)^{2}} .
$$

This expression is positive when $m \in\left(m_{1}, m_{2}\right)$, where $m_{1,2}=\frac{-n^{2}-n \pm\left(1+n^{2}\right) \sqrt{n}}{n(n-1)}$. I disregard the negative solution and note that $m_{2}=\frac{-n^{2}-n+\left(1+n^{2}\right) \sqrt{n}}{n(n-1)} \geq 1$ if $n>3.38$.

Proposition 1 In case of entry, collusion between the domestic owners is profitable if $n \geq 4$ and $m \in\left[1, m_{2}\right]$.

When the market is very concentrated, if there is at least on managerial firm in the market it is never profitable to be pure profit-seekers. This occurs because the profits accruing to the profit-seeking firms are lower than those associated to a (D) outcome, in which all firms are managerial.

Remark 2 If $n=3$ and $m=1$, collusion between domestic owners is never profitable.

Proposition 3 When collusion between domestic owners is profitable after entry, the entrants optimally set $\theta_{e}^{S}=(a-c) \frac{n-1}{n-m+n m+1}$, for all $e \in$ $\{1, \ldots, m\}$, and the incumbents set $\theta_{i}^{S}=0$ for all $i \in\{m+1, \ldots, n\}$.

After determining when the cartel is profitable, I want to assess the stability of the cartel between domestic owners. When all foreign owners set the amount of delegation according to (32) and all but one domestic owners set $\theta_{i}^{S}=0$, the optimal delegation of the domestic owner that deviates from the cartel is:

$$
\theta_{d}(m)=(a-c) \frac{n^{2}-1}{2 n(n-m+n m+1)}
$$




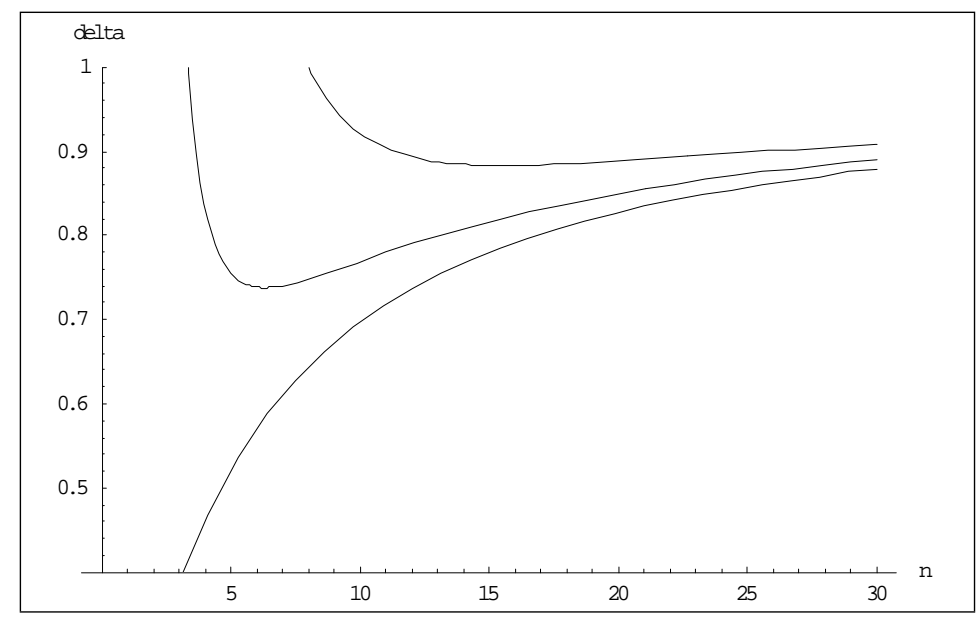

Figure 1: Critical value of the discount rate above which collusion between national owners is stable. The curves correspond, from bottom to top, to $m=0, m=1$ and $m=2$.

which entails the following deviation profit:

$$
\pi_{d}(m)=(a-c)^{2} \frac{\left(1+n^{2}\right)}{4 n(n-m+n m+1)^{2}}>\pi_{i}^{S}(m) .
$$

By considering trigger strategies, collusion between domestic owners is stable if

$$
\delta>\delta^{*}(n, m)=\frac{\pi_{d}(m)-\pi_{i}^{S}(m)}{\pi_{d}(m)-\pi^{D}},
$$

where the critical value of the discount function is given by the following expression:

$$
\delta^{*}(n, m)=\frac{(n-1)\left(1+n^{2}\right)^{2}}{\left(n^{2}-1-2 n m\right)\left(n^{3}+2 n^{2} m-2 n m+3 n^{2}+3 n+1\right)}
$$

Proposition 4 If $n \geq 4$ and $m \in\left[1, m_{2}\right)$, collusion between domestic owners is stable if $\delta>\delta^{*}(n, m)$.

In Fig. 1 the curves $\delta^{*}(n, 0), \delta^{*}(n, 1)$ and $\delta^{*}(n, 2)$ are drawn to illustrate how the stability of the (S) outcome depends on $\delta$ and $n$. For $\delta<\delta^{*}(n, 0)$ the (D) outcome always obtains, even when there is no entrant, because the 
domestic owners are too impatient to collude successfully. Between $\delta^{*}(n, 0)$ and $\delta^{*}(n, 1)$, the $(\mathrm{C})$ outcome obtains if there is no entry, and the (D) outcome obtains when there is at least one entrant. Between the curves $\delta^{*}(n, 1)$ and $\delta^{*}(n, 2)$, the (C) outcome emerges before entry (because $\delta>$ $\left.\delta^{*}(n, 0)\right)$, and the $(\mathrm{S})$ outcome is stable if there is one entrant, but unstable if there are two entrants (because $(n, \delta)$ is such that $\left.\delta^{*}(n, 1)<\delta<\delta^{*}(n, 2)\right)$.

For $m \geq 1, \delta^{*}(n, m)$ is non monotone in $n:$ it is decreasing for low values of $n$ and it is increasing when $n$ is large (see also Lambertini and Trombetta, 2002). Intuitively a stable cartel needs high discount rates when the total number of firms is low because $\pi_{d}(m)-\pi_{i}^{S}(m)$, the incentive to deviate from the cartel, is high. As $n$ increases, the gains from deviation decrease, while $\pi_{d}(m)-\pi^{D}$, the difference between the one-period profit from deviation and the punishment profit, grows rapidly. This makes collusion more and more appealing, and lower discount rates are required. If $n$ increases further, all profits decrease, but the gains from collusion decrease more rapidly than the punishment profits $\pi^{D}$ corresponding to the non-cooperative solution. This makes the cartel more unstable, and higher discount rates are required to sustain collusion.

With reference to condition (41), stability can also be assessed in terms of the critical number of firms that makes collusion between foreign owners stable. Let $m^{*}(n, \delta)$ be such a number, which is defined as

$m^{*}(n, \delta)=\operatorname{Max}\left\{\frac{-2 \delta n(n+1)+\left(1+n^{2}\right) \sqrt{\delta\left[\delta\left(n^{2}+1\right)-\left(n^{2}-1\right)\right]}}{2 \delta(n-1) n}, 1\right\}<m_{2}$.

In Fig. 2 the critical dimension of the fringe of managerial firms that makes the cartel between domestic owners unstable is drawn for $n \geq 4$. The horizontal line corresponds to $m=1$. For increasing values of $\delta$, the $m^{*}$ locus shifts upward, implying that, ceteris paribus, a larger fringe is needed to make the cartel unstable. Note that $m^{*} \geq 1$ if $\delta \geq \delta^{*}(n, 1)$, which means that one entrant can make the $(\mathrm{S})$ outcome stable if the domestic owners are patient enough, given the total number of firms, to sustain collusion.

Proposition 5 For $n \geq 4$ : 


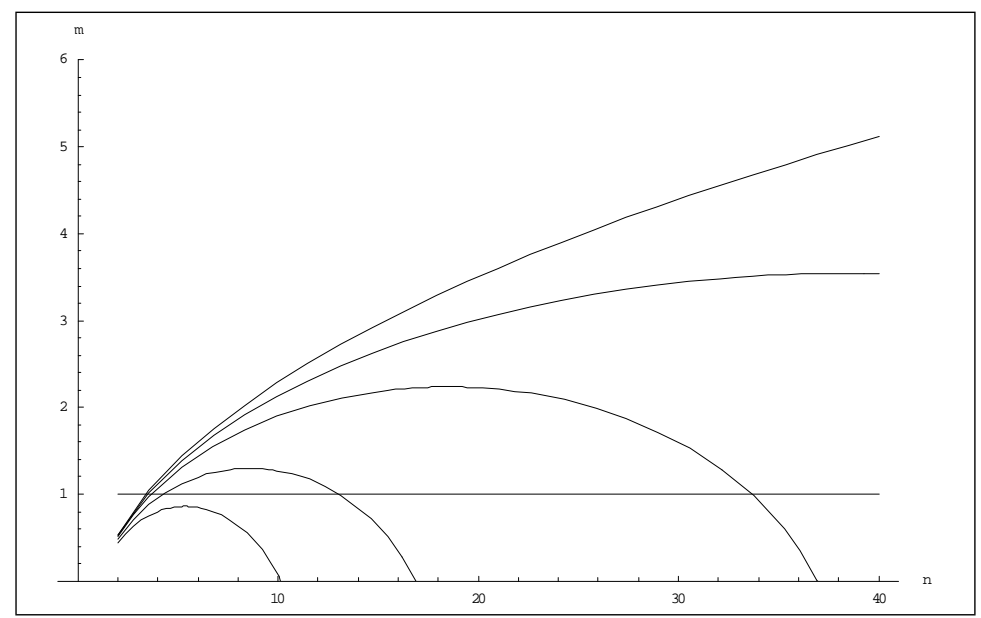

Figure 2: Plot of the critical dimension of $m^{* *}(n, \delta)$, the fringe ensuring stability to the cartel between national owners. Given $(n, \delta)$, the cartel is unstable if $m>m^{* *}(n, \delta)$ and stable otherwise.

- there exists a unique critical dimension of the fringe $m^{*}(n, \delta)$ such that, after entry of foreign managerial firms, collusion between owners is unstable if $m>m^{*}(n, \delta)$

- if $\delta>\delta^{*}(n, 1)$, then $m^{*}(n, \delta)>1$ is a non-monotone, strictly concave function of $n$

- if $\delta<\delta^{*}(n, 1)$ or, equivalently, $m^{*}(n, \delta)<1$, one entrant is enough to make the (S) outcome unstable

\section{Optimal number of entrants.}

Considering the welfare function of a domestic social planner, I now determine the number of entrants that maximizes the level of domestic welfare associated with the (D) outcome with $m \geq 1$ entrants and the (S) outcome with $m \geq 1$ entrants. Using the the results of the previous section, the levels of domestic social welfare are, respectively: 


$$
\begin{aligned}
N S W^{D}(m) & =(a-c)^{2} \frac{n\left(n^{3}+2 n-2 m\right)}{2\left(n^{2}+1\right)^{2}} \\
\text { if } m & \in\left[\min \left\{m^{*}(n, \delta), 1\right\}, n\right] \\
N S W^{S}(m) & =\frac{(a-c)^{2}}{(n+n m-m+1)^{2}}\left[n-m+\frac{1}{2}(n+m n-m)^{2}\right] \\
\text { if } n & \geq 4 \text { and } m \in\left[1, m^{*}(n, \delta)\right)
\end{aligned}
$$

Remark $6 N S W^{D}(m)$ is decreasing in $m ; N S W^{S}(m)$ is increasing in $m$.

The level of $N S W$ associated to the (D) equilibrium is decreasing in the number of entrants because the output does not depend on the number of entrants, but total profits do so. On the other hand, the level of social welfare associated to the (S) outcome increases with $m$ because the gains on consumer surplus (due to the aggressive output choices of the $m$ managerial firms) more than compensate for the losses in the domestic profits. Given the previous remark, the optimal choice of the domestic planner would be to choose $m^{*}$, given $n$ and $\delta$, in both cases. Yet, there exists an implicit constraint, in that $m$ must be an integer number. Let $m_{s}=f \operatorname{floor}\left(m^{*}(n, \delta)\right)$ be the integer part of $m^{*}(n, \delta)$ and $m_{D}=\operatorname{ceiling}\left(m^{*}(n, \delta)\right)^{5}$. For each outcome, the optimal number of firms is as follows:

Proposition 7 When collusion after entry is not stable and the (D) outcome obtains, domestic social welfare is maximum if $m=m_{D}$

Proposition 8 When collusion after entry is stable and the $(S)$ outcome obtains, domestic social welfare is maximum if $m=m_{S}$.

\section{Equilibrium selection}

The levels of $N S W$ for the (D) equilibrium with no entry, the (C) equilibrium with no entry, the (D) equilibrium with $m_{D}$ entrants and the $(\mathrm{S})$ equilibrium with $m_{S}$ entrants are, respectively:

\footnotetext{
${ }^{5}$ The floor and the ceiling functions are two functions which convert arbitrary real numbers to close integers. The floor function of a real number $x$ is a function that returns the highest integer less than or equal to $x$. Formally, for all real numbers $x$, floor $(x)=$ $\max \{n \in Z \mid n \leq x\}$. The ceiling function is the function that returns the smallest integer not less than $\mathrm{x}$, or, formally, ceiling $(x)=\min \{n \in Z \mid x \leq n\}$.
} 


$$
\begin{aligned}
N S W^{D}(0) & =(a-c)^{2} \frac{n^{2}\left(n^{2}+2\right)}{2\left(n^{2}+1\right)^{2}} \\
N S W^{C} & =(a-c)^{2} \frac{n(n+2)}{2(n+1)^{2}} \\
N S W^{D}\left(m_{D}\right) & =(a-c)^{2} \frac{n\left(n^{3}+2 n-2 m_{D}\right)}{2\left(n^{2}+1\right)^{2}} \\
N S W^{S}\left(m_{S}\right) & =(a-c)^{2} \frac{\left[n-m+\frac{1}{2}\left(n+n m_{S}-m_{S}\right)^{2}\right]}{\left(n+n m_{S}-m_{S}+1\right)^{2}}
\end{aligned}
$$

It is easy to check that the (D) outcome with no entry is associated to the highest level of domestic welfare where all firms are domestics and managerial. This outcome corresponds to the more competitive of the four cases, and it occurs when $\delta<\delta^{*}$. The (S) outcome with $m_{S}$ entrants yields the lowest domestic welfare and is not desirable. The social planner will try to avoid it either by not allowing any foreign firm to enter the market or by allowing $m_{D}$ foreign firms to enter and make the (S) outcome unstable. In the former case, a (D) outcome with no entry or a (C) outcome obtains, while in the latter a (D) outcome with $m_{D}$ entrants obtains. As the (D) outcome with no entry is the most desirable outcome, no policy intervention is needed when $\delta<\delta^{*}$. On the contrary, when $\delta>\delta^{*}$ it is optimal for the domestic planner to allow $m_{D}$ entrants in the market if $N S W^{D}\left(m_{D}\right)>N S W^{C}$.

Proposition 9 No foreign firm should be allowed to enter the market:

- if $\delta<\delta^{*}(n, 0)$,

- if $n \in\{2,3\}$,

- if $\delta>\delta^{*}(n, 1)$ and $N S W^{C}>N S W^{D}\left(m_{D}\right)$.

Proposition 10 It is optimal to allow $m_{D}$ foreign firms to enter the market

- if $\delta \in\left(\delta^{*}, \delta^{*}(n, 1)\right)$ and $n>3$

- if $\delta>\delta^{*}(n, 1)$ and $N S W^{C}<N S W^{D}\left(m_{D}\right)$. 
The propositions determine the conditions that should drive the decision of the domestic planner. To understand the logic, observe that if $\delta<\delta^{*}(n, 0)$, the (D) outcome with no entrants obtains. This is the equilibrium with the highest domestic welfare level, and thus no intervention is needed. If $\delta>\delta^{*}(n, 0)$, we must distinguish different cases by comparing $N S W^{C}$ (which occurs when $m=0$ and $\delta>\delta^{*}$ ) and $N S W^{D}\left(m_{D}\right)$ (which occurs when $\left.m=m_{D} \geq 1\right)$.

Case (a): $n \in\{2,3\}$. In this case the (C) outcome obtains before entry and the (D) outcome with $m \in\{1,2,3\}$ entrants. As $N S W^{C}>N S W^{D}(m)$ if $n<3.28$, no intervention is needed.

Case (b): $n>3$ and $\delta \in\left(\delta^{*}, \delta^{*}(n, 1)\right)$. In this case, before entry the (C) outcome obtains and, in case $m_{D}=1$, the (D) outcome with one entrant obtains. It is optimal to allow one managerial firm to enter the market because $N S W^{C}<N S W^{D}(1)$ for all $n$ : entry is desirable because it improves the economy by inducing a (D) equilibrium that is better than the $(\mathrm{C})$ outcome

Case (c): $\delta>\delta^{*}(n, 1)$. As for the previous case, the (C) outcome results before entry and the (D) outcome with $m_{D} \geq 2$ entrants results after entry. With respect to the previous case, note that $m_{D}$ changes as a function of $n$ and $\delta$ and the levels of domestic welfare must be explicitly computed and compared. To illustrate this point, in Fig. 3 I set $\delta=.85$ and I plot both $m^{*}$ and $m_{D}$ as functions of $n$. The jumps occur at $n=3.88$ (where $m_{D}$ becomes 2 ) and at $n=20.13$ (where $m_{D}$ comes back to one). In Fig. 4 I plot both $N S W^{D}\left(m_{D}\right)$ and $N S W^{C}$ to show graphically the relative rankings as functions of $n$. Now consider a market where $n=4$. We are in case (c) because $\delta=.85>\delta^{*}(n, 1)=.83$. With this configuration, $m^{*}(n, \delta)=1.02$ and $m_{D}=2$. The comparison between the two associated levels of domestic welfare yields $N S W^{C}=.48>N S W^{D}(2)=.47$, and it is optimal to let no entrant in. If instead $n=6, m_{D}$ would still be 2 , but we would get the opposite ranking as $N S W^{C}=.489<N S W^{D}(2)=.49$. In this case, the $(\mathrm{C})$ outcome is better than the (D) outcome with $m_{D}$ entrants and no intervention is needed.

\section{Conclusion}

The separation between ownership and control of market decisions significantly affects the competitive behavior of an oligopolist. In a Cournot 


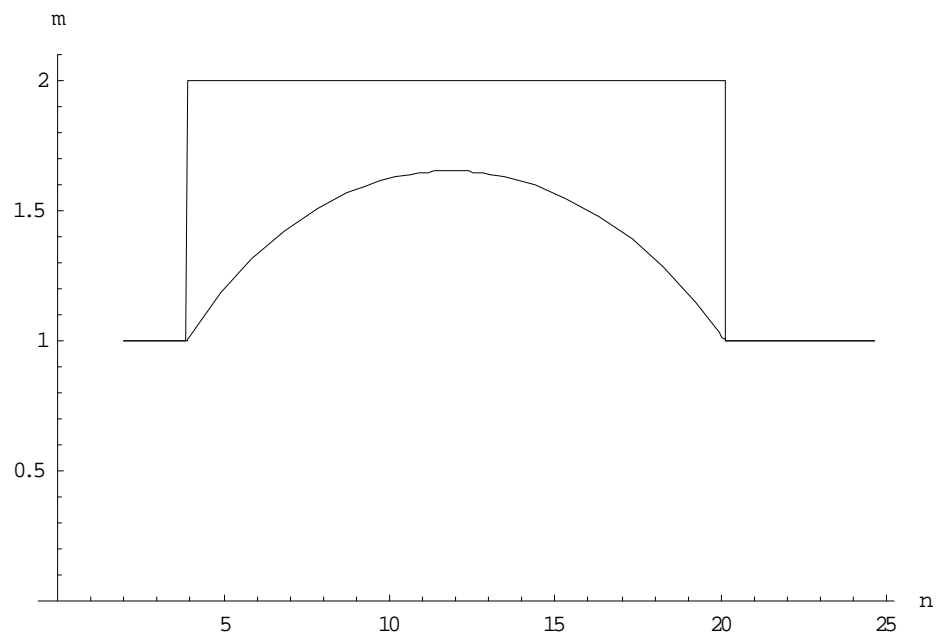

Figure 3: Plot of $m^{* *}(n, d)$ and $m_{D}$ as functions of $n$.

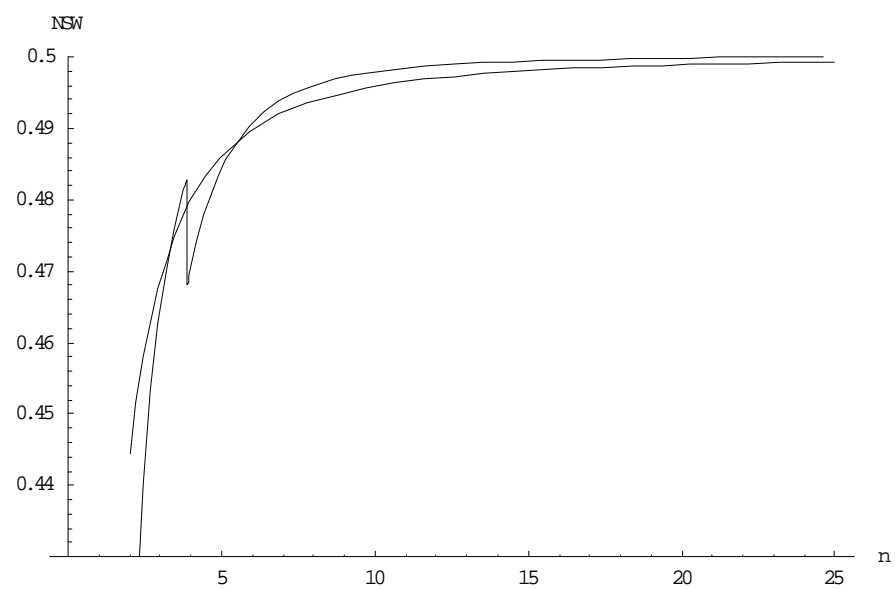

Figure 4: Comparison of the levels of national welfare for the $(\mathrm{C})$ outcome (smooth curve) and the (D) outcome with $m_{D}$ entrants (broken curve) when $\delta=.85$. 
oligopoly, when the incentive schemes of the managers are a mix of profits and sales, managers optimally behave aggressively by expanding their output. As this outcome is dominated by the Cournot Nash equilibrium, the owners of the firms might collude to reduce competition. I have omvestigated how a cartel between owners is affected by the existence of a fringe of firms that always delegate output choices to managers. Adopting the Vickers (1985) framework, I have shown that it is always possible to make unstable the cartel between owners by appropriately selecting the dimension of the fringe, and that the dimension of the fringe that ensures cartel stability is non-monotone in the total number of firms operating in the market.

The introduction of a fringe of managerial firms can be used by a planner in order to modify the equilibrium outcome. For example, a domestic planner might contemplate whether to allow foreign managerial firms to enter a domestic market where the owners of firms collude by adopting organizational structures that reduce competition.

\section{References}

[1] Basu, K., 1995. Stackelberg Equilibrium in Oligopoly: an Explanation based on Managerial Incentives. Economics Letters 49, 459-464.

[2] d'Aspremont, C., Jacquemin, A., Gabszewicz, J.J.,Weymark, J., 1983. On the Stability of Collusive Price Leadership. Canadian Journal of Economics 16, 17-25.

[3] Deneckere, R., 1983. Duopoly Supergames with Product Differentiation. Economics Letters 11, 37-42.

[4] Donsimoni, M.P., 1985. Stable Heterogeneous Cartels. Interdomestic Journal of Industrial Organisation 3, 451-467.

[5] Donsimoni, M.P., Economides, N., Polemarchakis, H., 1986. Stable Cartels. Interdomestic Economic Review 27, 317-327.

[6] Escrihuela-Villar, M., 2004. Cartel Sustainability and Cartel Stability. Working Papers 2004.44, Fondazione Eni Enrico Mattei. 
[7] Fershtman, C., 1985. Internal Organisations and Managerial Incentives as Strategic Variables in a Competitive Environment. Interdomestic Journal of Industrial Organisation 3, 245-253.

[8] Fershtman, C., Judd, K., 1987. Equilibrium Incentives in Oligopoly. American Economic Review 77, 927-940.

[9] Fershtman, C., Judd, K., Kalai, E., 1991. Observable Contracts: Strategic Delegation and Cooperation. Interdomestic Economic Review 32, $551-559$

[10] Friedman, J.W., 1971. A Non-Cooperative Equilibrium for Supergames. Review of Economic Studies 38, 1-12.

[11] Green, E.J., Porter, R.H., 1984, Noncooperative Collusion under Imperfect Price Information, Econometrica 52, 87-100.

[12] Katz, M.L. 1991. Game-Playing Agents: Unobservable Contracts as Precommitments. The RAND Journal of Economics 22, 307-328.

[13] Konishi, H., Lin P., 1999. Stable Cartels with a Cournot Fringe in a Symmetric Oligopoly, Keio Economics Studies 36, 1-10.

[14] Lambertini, L., Trombetta, M., 2002. Delegation and Firms' Ability to Collude. Journal of Economic Behavior and Organization 47, 359-373.

[15] Ross, T.W., 1992. Cartel Stability and Product Differentiation. Interdomestic Journal of Industrial Organization 10,1-13.

[16] Rotemberg, J., Saloner, G., 1986. A Supergame-Theoretic Model of Business Cycle and Price Wars during Booms. American Economic Review 76, 390-407.

[17] Rothschild, R., 1999. Cartel Stability when Costs are Heterogeneous. Interdomestic Journal of Industrial Organization 17, 717-734.

[18] Shaffer, S., 1985. Stable Cartels with a Cournot Fringe. Southern Economic Journal 61.

[19] Sklivas, S.D., 1987. The Strategic Choice of Managerial Incentives. RAND Journal of Economics 18, 452-458. 
[20] Thoron, S., 1998. Formation of a Coalition-Proof Stable Cartel. The Canadian Journal of Economics/Revue Canadienne d'Economique 31, $63-76$.

[21] Vickers, J., 1985. Delegation and the Theory of the Firm. Economic Journal 95, 138-147.

\section{Appendix}

To show that collusion between incumbents is not profitable when $m>\frac{n-1}{2}$, consider profit functions (29) and (30). If $m>\frac{n-1}{2}$, the optimal amount of delegation of domestic and foreign managers is as follows:

$$
\begin{aligned}
& \hat{\theta}_{e}=(a-c) \frac{n-1}{2+m+n m} \\
& \hat{\theta}_{i}=(a-c) \frac{1+2 m-n}{(2+m+n m)(n-m)} .
\end{aligned}
$$

Note that all owners always choose a positive amount of delegation. Substituting $\hat{\theta}_{e}$ and $\hat{\theta}_{i}$ in the manager's reaction functions (7) and rearranging, I obtain the output levels of, respectively, the domestic entrants and the foreign incumbents:

$$
\begin{aligned}
& \hat{q}_{e}(m)=(a-c) \frac{n}{2+m+n m} \\
& \hat{q}_{i}(m)=(a-c) \frac{1+m}{(n-m)(2+m+n m)}
\end{aligned}
$$

where $m$ in brackets signals that these outcomes depend on the number of entrants. The associated total output levels and individual profits are, respectively:

$$
\begin{aligned}
\hat{Q}(m) & =(a-c) \frac{(1+m+m n)}{2+m+n m} \\
\hat{\pi}_{e}(m) & =(a-c)^{2} \frac{n}{(1+n m-m+n)^{2}} \\
\hat{\pi}_{i}(m) & =(a-c)^{2} \frac{1}{(1+n m-m+n)^{2}}
\end{aligned}
$$


We are now ready to check whether collusion between domestic owners is profitable. Comparing $\hat{\pi}_{i}(m)$ and $\pi_{i}^{D}$ yields:

$\hat{\pi}_{i}(m)-\pi_{i}^{D}=-(a-c)^{2} \frac{(1+n)(n-m-1)\left(1+3 n m+m^{2} n-n^{2}-m n^{2}+m^{2} n\right)}{(n-m)(2+m+n m)^{2}\left(1+n^{2}\right)^{2}}$.

As all the terms in brackets are positive, the cartel is never profitable. 